IRSTI 27.35 .14

\author{
${ }^{1} \mathrm{~A}$. Issakhov, ${ }^{2} \mathrm{~T}$. Yang, ${ }^{3} \mathrm{~A}$. Baitureyeva \\ ${ }^{1}$ Faculty of Mechanical Mathematics, Al-Farabi Kazakh National University, \\ Almaty, Kazakhstan, e-mail: alibek.issakhov@gmail.com \\ ${ }^{3}$ Department of Design Engineering and Mathematics, Middlesex University, \\ London, United Kingdom, e-mail: T.Yang@mdx.ac.uk \\ ${ }^{3}$ Faculty of Mechanical Mathematics, Al-Farabi Kazakh National University, \\ Almaty, Kazakhstan, e-mail: baitureyeva.aiymzhan@gmail.com
}

\title{
CFD simulation of pollution dispersion from thermal power plants in the atmosphere
}

\begin{abstract}
This paper presents CFD simulation of pollution dispersion from a thermal power plant. Carbon dioxide was chosen as the scattering gas, as it constitutes the main share of emissions from the energy industry. The model was tested using experimental results performed using wind tunnel data available in the literature. A comparative analysis of the results of this article with experimental and numerical data was performed. It showed that the results of this article were closer to the experimental results than the calculations of previous authors. The minimum relative error with the experiment was less by $4.11 \%$ at the pipe exit and by $2.52 \%$ at a distance $\mathrm{x} / \mathrm{D}=3$ from the source, than other results. Based on this verification, the spread of pollution from thermal power plant (TPP) in real physical dimensions was modeled. The k-epsilon turbulence model was used taking into account buoyancy. The calculations were performed using the ANSYS Fluent 18.1 software package. As a result, the distance from the source was calculated, at which pollution will reach the ground surface $(\sim 2 \mathrm{~km})$. Obtained distance is quite big since this TPP is located in an area which is far from residential settlements and there are no natural or architectural obstacles around. Key words: Navier-Stokes equations, mass transfer, numerical modeling, air pollution, concentration, thermal power plant.
\end{abstract}

\section{Introduction}

Air pollution every year becomes an increasingly serious large-scale problem. Plants and various energy facilities (such as thermal power plants, nuclear power plants, etc.) produce a large amount of pollutants that dispersed in the atmosphere, damage the flora, fauna, buildings and harm human health. The European Environment Agency (2018) gives the following definition of air pollution: "the presence of contaminant or pollutant substances in the air that do not disperse properly and that interfere with human health or welfare, or produce other harmful environmental effects." [1].

According to the final emissions report for 2017, published in March 2018, global energy-related $\mathrm{CO}_{2}$ emissions have increased and reached a historic maximum. At the same time, special attention should be paid to the energy sector, since the share of energy is more than two thirds of total greenhouse gas emissions and more than $80 \%$ of $\mathrm{CO}_{2}$ emissions [2]. Therefore, in this paper, $\mathrm{CO}_{2}$ was selected as the main test substance of pollution. The background annual $\mathrm{CO}_{2}$ concentration on the Earth is equal to $400.88 \mathrm{ppm}=0.0004$ (mass fraction) [3].

To determine the extent of air pollution impact on the environment and people, it is important to take into account the physical principles affecting the movement and dispersion of pollutants [4].

Due to the rapid growth of computer capabilities, in particular, large-scale parallel computing, it becomes advisable to use computer simulation to calculate scientific and technical engineering problems. Nowadays technologies are rapidly developing, as a result of which their productivity has increased exponentially over time. 
According to the data, over the past 60 years, computing power has increased in productivity by 1 trillion times. [5]

Therefore, people use computational fluid dynamics to conduct large-scale computer modeling of important scientific and engineering topics [6-7].

The study of jet behavior in crossflow is important for various applications, especially for chimneys, because the interaction between the jet and crossflow fluids affects the pollution dispersion into the atmosphere [8].

A review and description of the works devoted to the study of the nature of jet motion in a crossflow is given in [9-14]. Early studies of jets in crossflow were devoted to the derivation of empirical equations for the flight path and the principles of scaling [15-18]. To this end, the authors conducted numerous experimental studies. Recent research in this area is described in $[19,20]$. Further, there have been many studies of vortex structures (vortex pairs rotating in opposite directions, horseshoe vortices); stability and destruction of the jet [21-22].

The purpose of this work was to assess the impact of emissions on the environment based on a numerical model of the spread of pollutants from sources. One of the pipes of Ekibastuz Thermal Power Plant-1 (Kazakhstan) was chosen as a real physical object of research [23]. Its height is 330 $[\mathrm{m}]$, the pipe diameter is $10[\mathrm{~m}]$.

\section{Mathematical model}

Computational fluid dynamics has proven to be an effective tool for modeling the behavior of jets in crossflow. Modeling of such problems is based on the resolution of the Navier-Stokes equations (the equation of continuity and the equation of motion) [24-25]. It was found that Reynolds-averaged Navier-Stokes equations (RANS) modeling, can qualitatively predict the behavior of the total flow and concentration [26]. Past studies have revealed that non-stationary large eddy simulation (LES) models provide good agreement with experimental results in pollutant dispersion problems [27]. However, the computational cost of this model is about 100 times higher than the cost required for the RANS model [28]. Important observations regarding RANS k-epsilon were noted in [29].

In present work, RANS k-epsilon model was used. Also, a comparative analysis of the obtained results with the experimental [30] and numerical [31] data was carried out. The SIMPLE method was chosen for the calculation. This method has been applied in multiple numerical studies and, when compared with experimental data, has shown good agreement. [29].

\section{Test problem}

A detailed description of the test problem and experiment is given in $[30,31]$. The test problem domain is a three-dimensional channel with a pipe inside it. The pipe diameter (jet width) was $\mathrm{D}=12.7$ $[\mathrm{mm}]$, which was used as a characteristic unit of length. The dimensions of the geometry are shown in Figure 1.

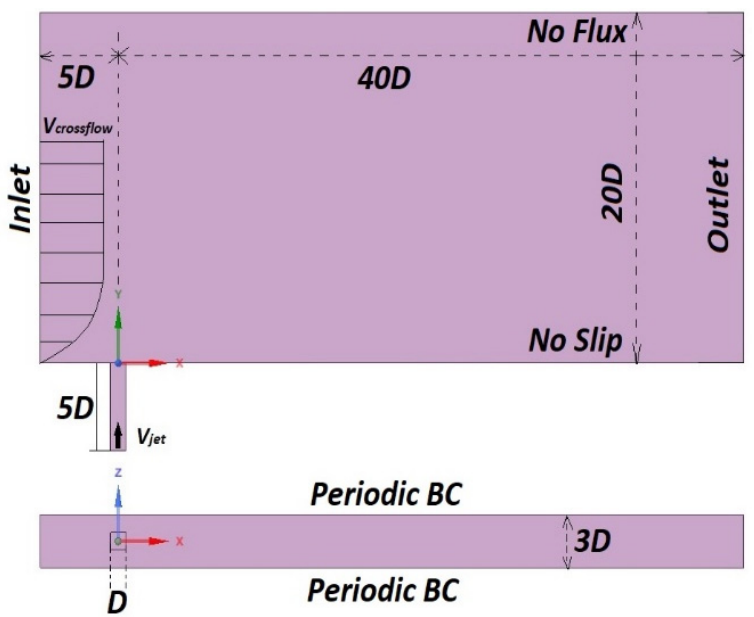

Figure 1 - Configuration of the computational domain of the test problem

An unstructured grid was constructed, the total number of nodes was 533697 (See Table 1). The ratio of the jet velocity to the velocity of the crossflow is denoted as $R=V_{\text {jet }} / V_{\text {crossflow }}$. In the present work, $\mathrm{R}=0.5$ was considered: the jet velocity was $5.5\left[\mathrm{~ms}^{-1}\right]$, the crossflow velocity was 11 $\left[m s^{-1}\right]$.

Table 1 - Number of grid points

\begin{tabular}{|c|c|}
\hline NI & 230 \\
\hline NJ & 100 \\
\hline NK & 21 \\
\hline Total body sizing & $0.0025[\mathrm{~m}]$ \\
\hline Total nodes & 533697 \\
\hline
\end{tabular}

Air was chosen as the main fluid material for the crossflow and the jet. The Reynolds number has been defined as: 


$$
R e_{j e t}=\rho V_{j e t} D / \mu=4700 .
$$

Five types of boundary conditions were used: inlet, outlet, periodic, no slip, no flux (see Figure 1). According to experimental data, the thickness of the boundary layer is equal to $2 \mathrm{D}$. The wind velocity profile was defined by a power law with exponent $1 / 7$ within the boundary layer and was set as constant $11\left[\mathrm{~ms}^{-1}\right]$ above it. Since a smooth surface was used in the experiment, the roughness height was zero.

a)
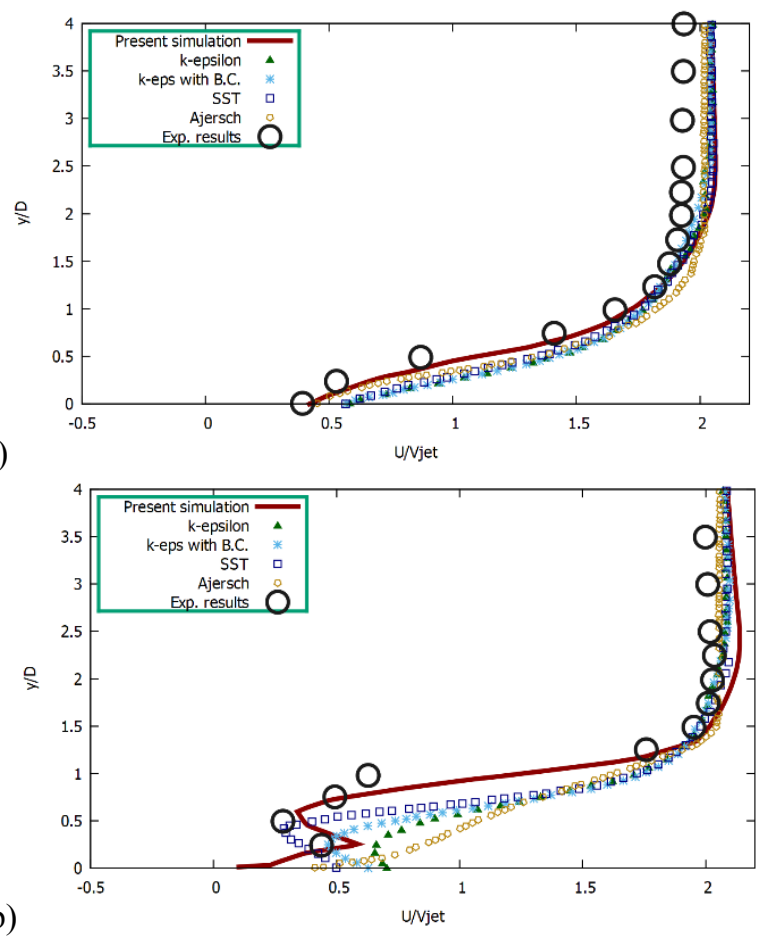

Figure 2 - Comparison of the obtained results with experiment data and calculations of other authors. (a) $\mathrm{x} / \mathrm{D}=0.0,(\mathrm{~b}) \mathrm{x} / \mathrm{D}=3.0$

Figure 2 shows a comparison of the numerical results of this study with experimental data and numerical solutions of other authors at various distances from the jet $(\mathrm{R}=0.5 ; \mathrm{x} / \mathrm{D}=0.0$ and $x / D=3.0)$. At the Figure 2,b the values of the red line $(\mathrm{u} / \mathrm{Vjet})$ at $\mathrm{y} / \mathrm{D}=0$ approach zero, while the plots of other authors in this interval show the values of $\mathrm{u} / \mathrm{Vjet} \sim 0.5-0.7$. A zero value is more reliable from a physical point of view, as this is a near-wall field. Also, in this region $(y / D \sim 0-1)$ the relative errors of present simulation are smaller, than others (see Table 2). Based on this data, the solutions obtained in this work turned out to be more accurate than the calculations obtained by other authors [30, 31]. The reason is the quality of the grid: in this work, an unstructured grid was used (the number of nodes was 533 697), while in [31] a structured grid was used (the number of nodes was 265000 ).

Table 2 - Relative errors of numerical simulations for $\mathrm{R}=0.5$

\begin{tabular}{|c|c|c|c|c|}
\hline & \multicolumn{2}{|c|}{ Min. relative error } & \multicolumn{2}{c|}{ Max. relative error } \\
\hline $\mathbf{x} / \mathbf{D}$ & 0.0 & 3.0 & 0.0 & 3.0 \\
\hline k-epsilon & $6.78 \%$ & $7.54 \%$ & $87.74 \%$ & $207.23 \%$ \\
\hline k-eps with BC & $6.57 \%$ & $6.2 \%$ & $85.16 \%$ & $169.66 \%$ \\
\hline SST & $6.57 \%$ & $7.9 \%$ & $72.9 \%$ & $170.1 \%$ \\
\hline Ajersch & $9.65 \%$ & $8.32 \%$ & $51.37 \%$ & $279.52 \%$ \\
\hline Present paper & $2.46 \%$ & $3.68 \%$ & $22.58 \%$ & $89.13 \%$ \\
\hline
\end{tabular}

\section{Ekibastuz thermal power plant-1: full-scale emission distribution modeling}

After verification and validation of the numerical algorithm, pollution dispersion from a real power plant (TPP) in full scale dimensions was modeled. Ekibastuz Thermal Power Plant-1 (Kazakhstan) was chosen as a real physical object of research (Figure 3). The power plant consists of a main building and two pipes. The dimensions of the main building are: length $-500 \mathrm{~m}$, width -132 $\mathrm{m}$, height $-64 \mathrm{~m}$. The height of the chimneys is 300 meters (built in 1980) and 330 meters (built in 1982), the exit pipe diameter for each is 10 meters. The 3D computational domain has dimensions $8000 \times 2496 \times 3000 \mathrm{~m}$ and the distance between the domain inlet and tallest pipe is $2000 \mathrm{~m}$. Also, the tallest pipe is located in the origin of the coordinate system (Figure 4). 


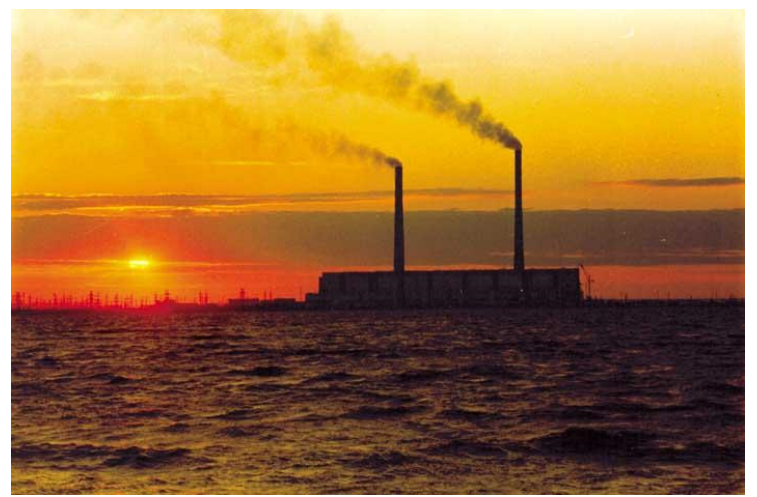

Figure 3 - Ekibastuz Thermal Power Station 1 (Kazakhstan, Ekibastuz city)

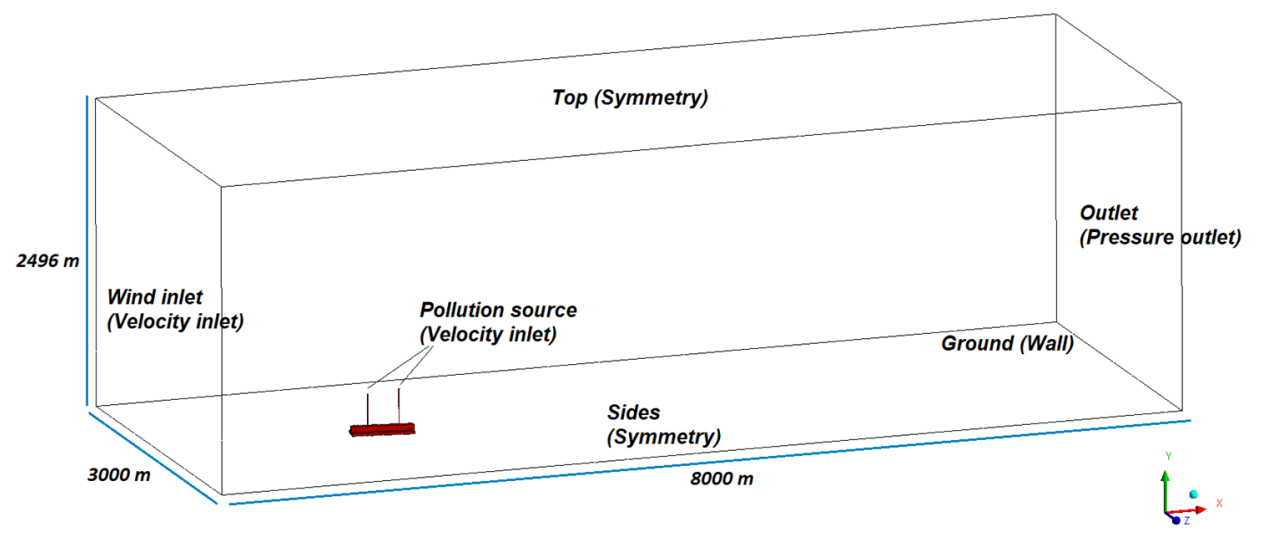

Figure 4 - Computational domain and boundary conditions for the Ekibastuz TPP simulation

a)

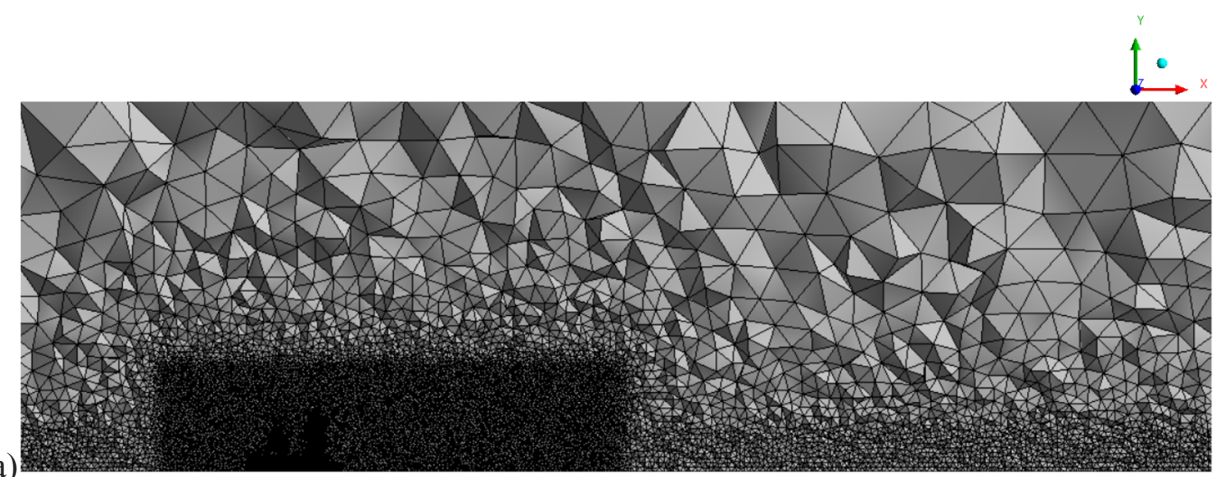

b)

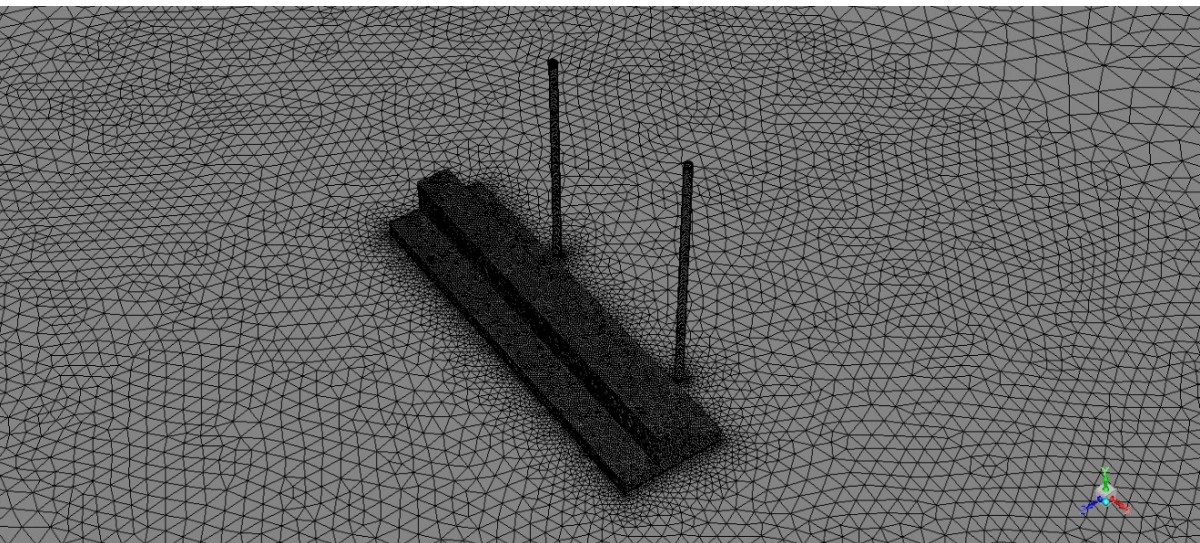

Figure 5 - Computational mesh of Ekibastuz TPP model: (a) cross-section view, (b) scaled view 
The grid was built on the same principle as in the test problem, i.e. refined in the area of the pollution movement trajectory (Figure 5).

Before calculations, mesh sensitivity analysis was performed. According to the results, the grid consisting of 5,193,038 triangular elements was chosen as the main grid for further calculations.

The distance $Z_{P}$ from the center point $P$ of the wall-adjacent cells to the ground surface (bottom of domain) is $0.49 \mathrm{~m}$, there was set inflation with the growth rate coefficient 1.2 since this is exactly the size of the first cell (height of first cell $<1 \mathrm{~m}$ ) that was recommended previously for an accurate simulation of the atmospheric boundary layer [29].

Since in this case it was not possible to measure experimentally the profile of velocity $u$, turbulence kinetic energy $k$ or dissipation rate $\varepsilon$, their initial profiles were set according to the [33], which describes the profiles of these components that are most suitable for modeling wind engineering problems.

$$
\begin{gathered}
u=\frac{u_{*}}{\kappa} \ln \left(\frac{y+y_{0}}{y_{0}}\right) \\
k=\frac{u_{*}^{2}}{\sqrt{C_{\mu}}} \\
\varepsilon=\frac{u_{*}^{3}}{\kappa\left(y+y_{0}\right)}
\end{gathered}
$$

Where $C_{\mu}=0.09, \quad y_{0}=0.2, \kappa=0.4, \quad u_{*}-$ friction velocity, which is calculated as:

$$
\mathrm{u}_{*}=\frac{\kappa \mathrm{u}_{\mathrm{ref}}}{\ln \left(\mathrm{y}_{\mathrm{ref}}+\mathrm{y}_{0}\right)}
$$

Here $u_{\text {ref }}$ was set to $7 \mathrm{~m} / \mathrm{s}$, according to the meteorological data and the wind rose presented in Figure 6. $y_{\text {ref }}=10 \mathrm{~m}$ since air measurements as a rule are made at this height. According to these data, the wind most often blows from the southwest (more than 288 hours per year), therefore this direction was chosen for calculations.

The temperature of the ground was set to be equal to the maximum average temperature for the year: 28 degrees. According to the meteorological data of Ekibastuz city, this temperature is set in July (Figure 7).

The emission temperature was set to $315^{\circ} \mathrm{C}$. Emission rate is $31.5 \mathrm{~m} / \mathrm{s}$. Thus, the momentum ratio is $\mathrm{M}=\mathrm{W}_{\mathrm{S}} / \mathrm{U}_{\mathrm{H}}=4.5$, where $\mathrm{W}_{\mathrm{S}}$ is the vertical exhaust velocity and $U_{H}-$ the horizontal wind velocity at the reference height $(10 \mathrm{~m})$. According to the data, the following substances are released into the atmosphere from the Ekibastuz TPP per year (Table 3).

Table 3 - Emissions from Ekibastuz TPP (2016)

\begin{tabular}{|c|c|c|}
\hline Type of pollutants & Unit & $\begin{array}{c}\text { Amount of } \\
\text { emissions }\end{array}$ \\
\hline $\mathrm{NO}_{\mathrm{X}}$ & tons & 54,700 \\
\hline $\mathrm{SO}_{2}$ & tons & 132,900 \\
\hline $\mathrm{CO}$ & tons & 2,800 \\
\hline Particulate matters & tons & 28,000 \\
\hline $\begin{array}{c}\text { Persistent organic } \\
\text { pollutants }\end{array}$ & tons & - \\
\hline $\begin{array}{c}\text { Volatile organic } \\
\text { pollutants }\end{array}$ & tons & 115.4 \\
\hline $\mathrm{CO}_{2}$ & $\begin{array}{c}\text { thousand } \\
\text { tons }\end{array}$ & 24150.7 \\
\hline
\end{tabular}

Thus, the share of $\mathrm{CO}_{2}$ in emissions is $99.1 \%$ and therefore the distribution of this gas was chosen for calculations.

\section{Results}

Figure 8 shows the vertical concentration profiles at various distances $(\mathrm{x} / \mathrm{H}=5,10,15$ and 20 , where $\mathrm{H}=300 \mathrm{~m}$ ) from the pollution sources for the default Schmidt number value of 0.7. Due to dissipation, the gas concentration decreases with increasing distance from the source. For comparison, the maximum concentration at the distance $\mathrm{x} / \mathrm{H}=20$ is almost 13 times less than the maximum concentration at the distance $\mathrm{x} / \mathrm{H}=5$ from the source. One can also notice that with increasing distance from source the height of the maximum concentration also increases. Thus, if at $\mathrm{x} / \mathrm{H}=5$ the maximum concentration point was at the height $\mathrm{y} / \mathrm{H}=2(600 \mathrm{~m})$, then at $\mathrm{x} / \mathrm{H}=20$ the maximum concentration point is at the height $\mathrm{y} / \mathrm{H}=3$ (900 m).

Figure 9 illustrates the ground-level downstream concentration profile along the $\mathrm{x}$-axis. According to the plot, the pollution reaches the earth at a distance of about $\mathrm{x}=1.5 \mathrm{~km}$, which is about $1753 \mathrm{~m}$ from a lower stack and $1500 \mathrm{~m}$ from a high stack. The maximum concentration reaches about $0.04 \mathrm{ppm}$, which is a fairly optimal level of pollution for human health. Figure 10 illustrates the comparison 
of ground-level lateral concentration profiles for different $\mathrm{Sc}$ numbers $(\mathrm{Sc}=0.7,1.0,1.2$ and 1.4). For $\mathrm{Sc}=0.7$, the concentration level is almost 2.5 times higher than with $\mathrm{Sc}=1.2$ and almost 2.78 than in the other cases $(\mathrm{Sc}=1.4$ and 1.0). Figure 11 illustrates the iso-surfaces of the pollution spreading. Due to dispersion, pollution dissipates with increasing distance from the source.

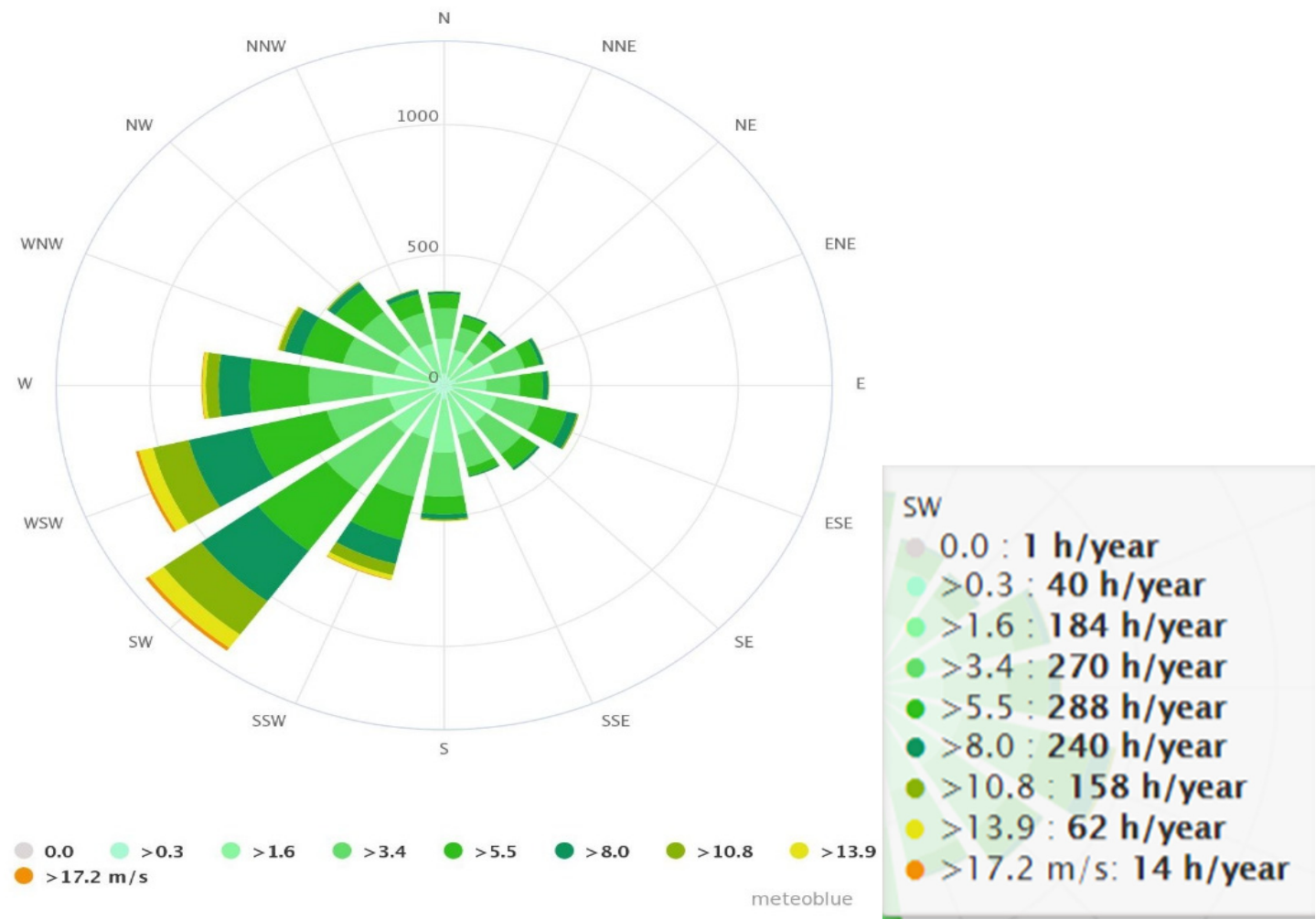

Figure 6 - Wind rose of the Ekibastuz city

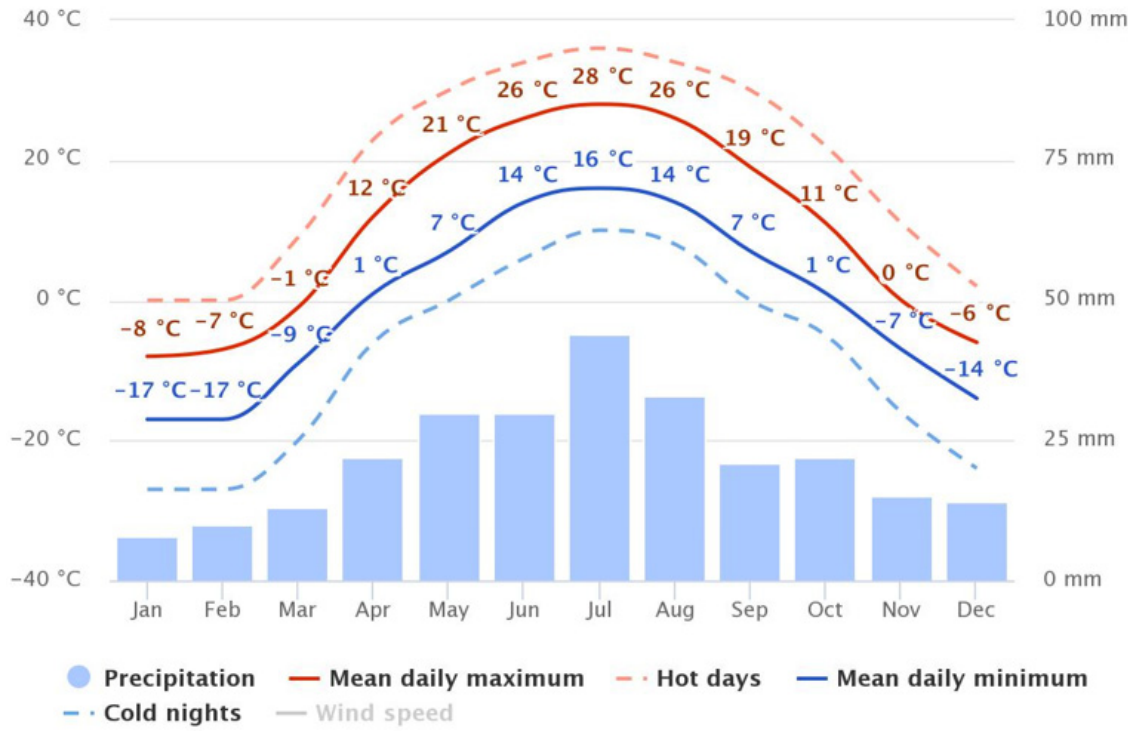

Figure 7 - Annual temperature of Ekibastuz city 


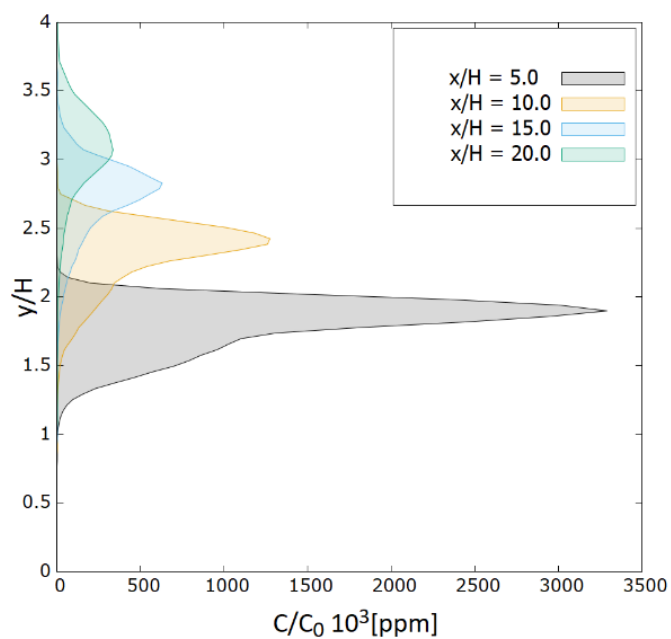

Figure 8 - Vertical concentration profiles at various distances from the pollution sources at central cross section $(\mathrm{z} / \mathrm{H}=0)$.

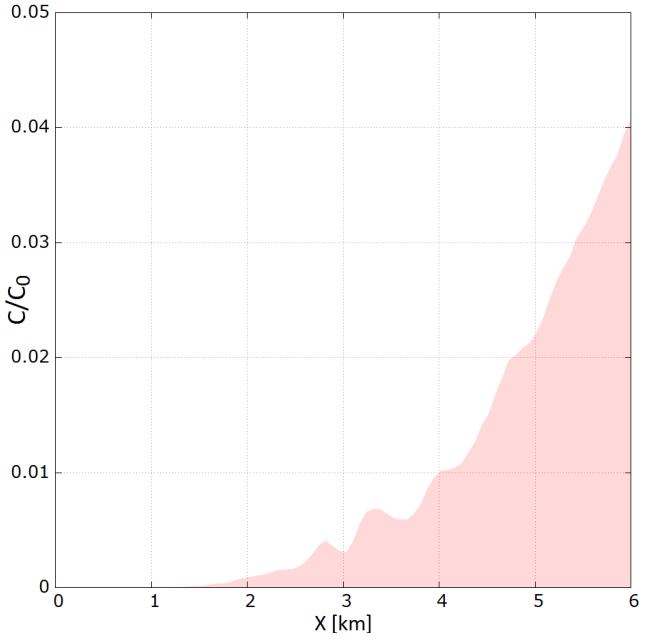

Figure 9. Ground-level $(\mathrm{y}=0)$ downstream concentration profile

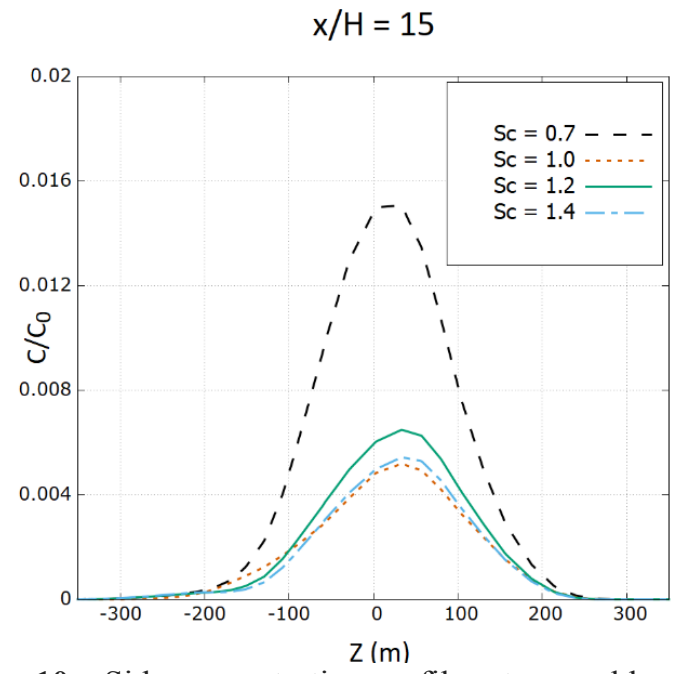

Figure 10 - Side concentration profiles at ground level $(\mathrm{y}=0)$ for different values of the Schmidt number $(\mathrm{Sc})$

\section{Conclusions}

The purpose of the study was to investigate the dynamics of the pollution dispersion. The mathematical model and numerical algorithm were tested using an experimental test problem. The results were closer to the experimental, compared with the data of other authors. Using the example of a real thermal power plant, $\mathrm{CO}_{2}$ dispersion was modeled. The k-epsilon model was used without any additional dispersion models. As a result, it was determined at what distance from the source the pollution accumulates on the ground surface.

According to the obtained data, with increasing distance from the source, the concentration of pollution spreads more widely under the influence of diffusion. 


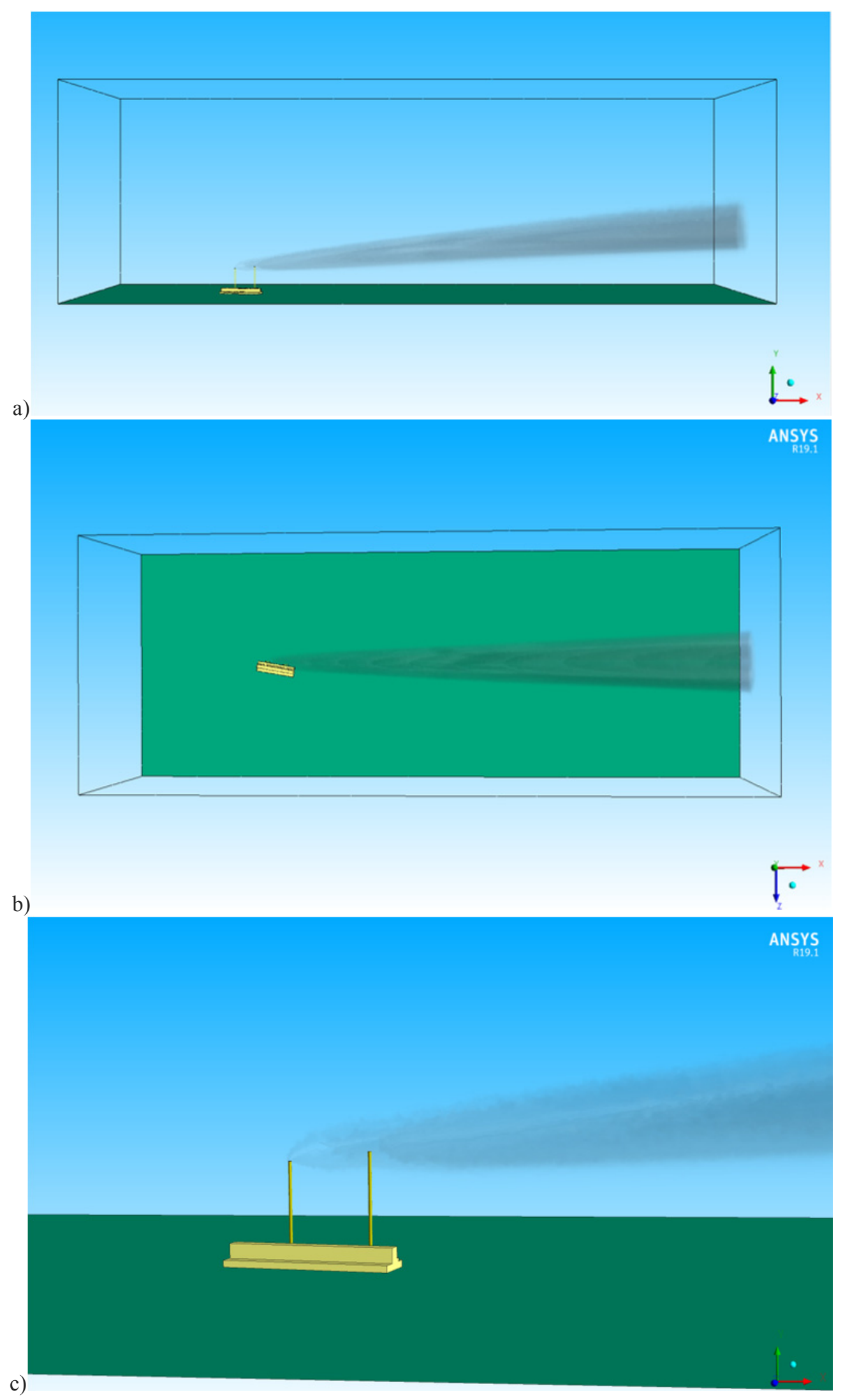

Figure 11 - Iso-surfaces of the mean concentration $\mathrm{C} / \mathrm{C}_{0}=0.01(\mathrm{Sc}=0.7)$ 
The farther the distance from the pipe, the lower the concentration of the substance. The various Sc numbers were tested for gas dispersion modelling, $\mathrm{Sc}=0.7$ showed the highest levels of concentration.

Thus, the obtained numerical data may allow to predict the optimal distance from residential areas for the construction of thermal power plants, at which the concentration of emissions will remain at a safe level in the future.

\section{References}

1. ECSC. (2018). Glossary: Primary \& Secondary pollutant. [online] Available at: http://ec.europa.eu/health/scientific_committees/opi nions_layman/en/indoor-air-

pollution/glossary/pqrs/primary-pollutant-

secondary-pollutant.htm (Accessed 5 Jul. 2018).

2. International Energy Agency (IEA). CO2

Emissions from Fuel Combustion; 2018

3. $\mathrm{CO} 2$ Earth. Annual CO2 Data, [online] Available at: https://www.co2.earth/annual-co2 Accessed: (15 January 2019)

4. Zavila O. Physical Modeling of Gas Pollutant Motion in the Atmosphere, Advances in Modeling of Fluid Dynamics, Dr. Chaoqun Liu (Ed.), InTech, 2012

5. Visual Capitalist. (2017). Visualizing the Trillion-Fold Increase in Computing Power. [online] Available

at:

https://www.visualcapitalist.com/visualizing-

trillion-fold-increase-computing-power (Accessed: 15 January 2019)

6. Jiangfei $Z$. "The new direction of computational fluid dynamics and its application in industry”, J. Phys.: Conf. Ser. 1064 012060, 2018

7. "Computational Fluid Dynamics Past, Present and Future". [online] Available at: http://aerocomlab.stanford.edu/Papers/NASA_Presentation_20 121030.pdf (Accessed: 15 January 2019 )

8. Rek Z. et al. "Numerical simulation of gas jet in liquid crossflow with high mean jet tocrossflow velocity ratio ". Chemical Engineering Science 172 (2017) 667-676

9. Margason, R. J. 1993 Fifty years of jet in crossflow research. In AGARD Symp. on a Jet in Cross Flow, Winchester, UK. AGARD CP 534.

10. Broadwell, J. E. , Breidenthal, R. E. 1984 Structure and mixing of a transverse jet in incompressible flow. J. Fluid Mech. 148, 405-412.

11. Karagozian, A. R. 1986 An analytical model for the vorticity associated with a transverse jet. AIAA J. 24, 429-436.
12. Hasselbrink, E.F., Mungal, M.G. 2001 Transverse jets and jet flames. Part 1. Scaling laws for strong transverse jets. J. Fluid Mech. 443, 1-25.

13. Muppidi, S., Mahesh, K. 2005 Study of trajectories of jets in crossflow using direct numerical simulations. J. Fluid. Mech. 530, 81-100.

14. Muppidi, S., Mahesh, K. 2008 Direct numerical simulation of passive scalar transport in transverse jets. J. Fluid Mech., 598, pp. 335-360.

15. Callaghan, E.E., Ruggeri, R.S., 1948. Investigation of the penetration on an air jet directed perpendicularly to an air stream.

16. Margason, R.J., 1968. The Path of a Jet Directed at Large Angles to a Subsonic Free Stream. Langley Research Center.

17. Golbitz, W.C., 1980. Time Dependent Navier-Stokes Solution of a Turbulent Gas Jet Ejected from a Rectangular Orifice into a HighSubsonic Crossflow. Faculty of the School of Engineering of the Air Force Institute of Technology.

18. Cutler, P.R.E., 2002. On the Structure and Mixing of a Jet in Crossflow. The Universe of Adelaide.

19. Erdem E., Kontis K., Saravanan S. Penetration characteristics of air, carbon dioxide and helium transverse sonic jets in mach 5 cross flow Sensors (Switzerland), 14 (2014), pp. 23462-23489.

20. Cambonie T., Gautier N., Aider J.L. Experimental study of counter-rotating vortex pair trajectories induced by a round jet in cross-flow at low velocity ratios Exp. Fluids, 54 (2013), pp. 1-13.

21. Karagozian, A.R., 2014. The jet in crossflow. Phys. Fluids 26.http://dx.doi.org/10.1063/1.4895900

22. Fric T.F., Roshko A. Vortical structure in the wake of a transverse jet J. Fluid Mech., 279 (1994), pp. 1-47,

23. Wikipedia, "Ekibastuz_GRES-1". [online] Available at: https://en.wikipedia.org/wiki/ Ekibastuz GRES-1 (Accessed: 15 January 2019)

24. Ferziger J. H., Peric M. Computational Methods for Fluid Dynamics. Springer; 3rd edition, 2013, -p. 426

25. Chung T. J. Computational Fluid Dynamics. Cambridge University Press, 2002 - p. 1012.

26. Tominaga, Y., Stathopoulos, T., 2009. Numerical simulation of dispersion around an isolated cubic building: comparison of various types of k-e models. Atmospheric Environment 43, 32003210 .

27. M. Chavez et al., "Near-field pollutant dispersion in the built environment by CFD and 
wind tunnel simulations". J. Wind Eng. Ind. Aerodyn. 99 (2011) 330-339

28. Cheng, Y., Lien, F.S., Yee, E., Sinclair, R., 2003. A comparison of large eddy simulations with a standard k-e RANS model for the prediction of a fully developed turbulent flow over a matrix of cubes. Journal of Wind Engineering and Industrial Aerodynamics 91, 1301-1328.

29. Blocken B. et al., "Numerical evaluation of pollutant dispersion in the built environment: Comparisons between models and experiments". J. Wind Eng. Ind. Aerodyn. 96 (2008) 1817-1831

30. Ajersch, P., Zhou, J. M., Ketler, S., Salcudean, M., and Gartshore, I. S., "Multiple Jets in a Crossflow: Detailed Measurements and Numerical Simulations," International Gas Turbine and Aeroengine Congress and Exposition, ASME Paper 95-GT-9, Houston, TX, June 1995, pp. 1-16.

31. Keimasi M.R., Taeibi-Rahni M., "Numerical Simulation of Jets in a Crossflow Using Different Turbulence Models", AIAA journal, Vol. 39, No. 12, December 2001

32. ANSYS Fluent Theory Guide 15, ANSYS Ltd., 2013.

33. Richards, P.J., Hoxey, R.P., 1993. Appropriate boundary conditions for computational wind engineering models using the $\mathrm{k}-\varepsilon$ turbulence model. J. wind Eng. ind. aerodyn. 46, 145-153. 